\title{
Efficacy of a Solution-Based Approach for Making Sodalite Waste Forms for an Oxide Reduction Salt Used in the Reprocessing of Used Uranium Oxide Fuel
}

\author{
Brian J. Riley, ${ }^{* \dagger}$ David A. Pierce, ${ }^{\dagger}$ Steven M. Frank, ${ }^{\ddagger}$ Josef Matyášs, ${ }^{\dagger}$ Carolyne A. Burns ${ }^{\dagger}$ \\ ${ }^{\dagger}$ Pacific Northwest National Laboratory, Richland, WA 99352 \\ ${ }^{\ddagger}$ Idaho National Laboratory, Idaho Falls, ID 83402
}

Keywords: sodalite, electrochemical, lithium chloride, oxide reduction

\begin{abstract}
This paper describes the various approaches attempted to make solution-derived sodalite with a $\mathrm{LiCl}-\mathrm{Li}_{2} \mathrm{O}$ oxide reduction salt used to dissolve used uranium oxide fuel so the uranium can be recovered and recycled. The approaches include modified sol-gel and solutionbased synthesis processes. As-made products were mixed with 5 and 10 mass $\%$ of a $\mathrm{Na}_{2} \mathrm{O}-\mathrm{B}_{2} \mathrm{O}_{3^{-}}$ $\mathrm{SiO}_{2}$ glass binder and these, along with product without a binder, were heated using either a cold-press-and-sinter method or hot uniaxial pressing. The results demonstrate the limitation of sodalite yield due to the fast intermediate reactions between $\mathrm{Na}^{+}$and $\mathrm{Cl}^{-}$to form halite in solution and $\mathrm{Li}_{2} \mathrm{O}$ and $\mathrm{SiO}_{2}$ to form lithium silicates (e.g., $\mathrm{Li}_{2} \mathrm{SiO}_{3}$ or $\mathrm{Li}_{2} \mathrm{Si}_{2} \mathrm{O}_{5}$ ) in the calcined and sintered pellets. The results show that pellets can be made with high sodalite fractions in the crystalline product ( $\sim 92$ mass\%) and low porosities using a solution-based approach and this $\mathrm{LiCl}-\mathrm{Li}_{2} \mathrm{O}$ salt but that the incorporation of $\mathrm{Li}$ into the sodalite is low.
\end{abstract}

\section{INTRODUCTION}

The current US nuclear fuel process is an open, or once-through, fuel cycle where the

*Corresponding author: Brian J. Riley; brian.riley@pnnl.gov; +1 (509)372-4651 (phone), +1 (509)372-5997 (fax) 
spent nuclear fuel, or fuel that is no longer useful in sustaining a nuclear fission reaction, is left to decay in storage for the indefinite future. Other fuel cycle options include some degree of recycle to increase fuel source utilization and reduce the quantity of long-lived isotopes in the fuel with limited, or no, separations steps. A few different options have been proposed to increase the efficiency of the used nuclear fuel recycling process. In one option for oxide fuel, the used nuclear fuel is dissolved in a molten alkali or alkaline earth chloride salt within an electrorefiner, and the reusable fuel is separated from the salt and fission products using an electrochemical process [1-8].

One particular electrochemical process for used oxide fuel utilizes a mixture of $\mathrm{LiCl}-\mathrm{Li}_{2} \mathrm{O}$ where the electrolysis of $\mathrm{Li}_{2} \mathrm{O}$ and the reduction of uranium oxide to metal occur simultaneously at the cathode [8]. This $\mathrm{LiCl}-\mathrm{Li}_{2} \mathrm{O}$ salt is referred to as an oxide reduction (OR) salt. The electrolysis of $\mathrm{Li}_{2} \mathrm{O}$ generates $\mathrm{Li}^{+}$and $\mathrm{O}^{2-}$, where the $\mathrm{Li}^{+}$strips the oxygen off of the $\mathrm{UO}_{2}$ or $\mathrm{U}_{3} \mathrm{O}_{8}$ so that the uranium can be recovered as a metal $\left(\mathrm{U}^{0}\right)$ as seen in Equation (1) [8]. Once the uranium is recovered, the salt can be recycled until the concentrations of alkali (i.e., Cs), alkaline earth (i.e., $\mathrm{Ba}, \mathrm{Sr}$ ), and halide (i.e., I) fission products, in addition to the bonded $\mathrm{Na}$ from the fuel, reach operating limits; at this point, the salt will require disposal.

$$
\begin{gathered}
\mathrm{Li}_{2} \mathrm{O} \rightarrow 2 \mathrm{Li}^{+}+\mathrm{O}^{2-} \\
\mathrm{UO}_{x}+2 x \mathrm{Li}^{+} \rightarrow \mathrm{U}^{0}+x \mathrm{Li}_{2} \mathrm{O}
\end{gathered}
$$

One disposal option for this salt is a synthetic sodalite. While the composition of sodalite is generally very flexible [9], the baseline ceramic waste form is fabricated with the simplified composition of $\mathrm{R}_{8}^{\mathrm{I}}\left(\mathrm{AlSiO}_{4}\right)_{6} \mathrm{~A}_{2}$, where $\mathrm{R}^{\mathrm{I}}$ is an alkali and $\mathrm{A}$ is a halide. Although sodalite is easier fabricated with $\mathrm{Na}^{+}$, it is possible to make it with large fractions of $\mathrm{Li}^{+}$[10-21]. Also, sodalites have been synthesized with both large fractions of $\mathrm{Li}^{+}$as well as $\mathrm{Cl}^{-}, \mathrm{Cl}$-containing 
oxyanions, or other halides $[10,11]$. Additionally, the iodine present in the OR salt can be immobilized in sodalite [22-26] but the alkaline earth components (i.e., $\mathrm{SrCl}_{2}$ and $\mathrm{BaCl}_{2}$ ) will likely incorporate into the glass binder as oxides rather than in the sodalite network as has been observed in the baseline sodalite waste form studies.

One limitation to the approaches provided in the literature for incorporating $\mathrm{Li}^{+}$into sodalite is that this was often achieved by heating a natural $\mathrm{NaCl}$-based sodalite in the presence, and often in an overabundance, of $\mathrm{LiCl}$ at temperatures of $\sim 800{ }^{\circ} \mathrm{C}$ to complete the ion exchange process [17-20]. It is unlikely that this type of process would pose issues for the volatile constituents in the OR salt such as iodine and cesium as per previous experience with the baseline ceramic waste form [27]. However, the loss of volatile constituents would be a drawback to this approach.

Another approach to incorporating $\mathrm{Li}$ into sodalite includes low temperature ion exchange but this also appears to require very high concentrations of $\mathrm{LiCl}$ or other $\mathrm{Li}$-salts like $\mathrm{LiNO}_{3}$, according to the literature [11, 14-16]. Applying these methods to immobilize the OR salt would require that the ionic contribution from the OR salt be more apt to substitute into the host sodalite for the existing ions and it is unlikely that this could be achieved without high processing temperatures. Thus, in order to design a process suitable to incorporate the OR salt into sodalite, the work presented here was focused on assessing various low temperature solution-based approaches. The variables included different silica sources (i.e., tetraethyl orthosilicate, colloidal silica), alkali aluminate powders (i.e., $\mathrm{NaAlO}_{2}, \mathrm{LiAlO}_{2}$ ), calcining temperatures (i.e., 500 and $600{ }^{\circ} \mathrm{C}$ ), precursor types (e.g., inorganic, organic, liquid, powdered), loadings of glass binder (i.e., 0, 5, 10 mass\%), and consolidation methods (i.e., cold-press-andsinter and hot uniaxial pressing). 
Several different methods can be used to make sodalite and they include (1) hightemperature structural conversion of zeolite 4A with occluded salt [28-31], (2) hydrothermal synthesis (elevated pressures and temperatures) [32, 33], (3) low-temperature solution-based synthesis [9, 34-36], and (4) sol-gel processing. All of these methods include a range of potential precursors, temperatures, pressures, and reaction times with each having advantages and disadvantages. In all cases, the products can be mixed with a glass binder to help with densification and to immobilize components from the waste that cannot be easily incorporated into the sodalite network, e.g., lanthanides, alkaline earths.

The well-known reaction used for the baseline ceramic waste form is presented in Equation (2) where the traditional $\mathrm{LiCl}-\mathrm{KCl}$ salt is hypothetically replaced with pure $\mathrm{LiCl}$ to represent the implementation of this technique for immobilizing the OR salt. However, while this approach has been successfully implemented for the $\mathrm{LiCl}-\mathrm{KCl}$ eutectic salt, it has not appeared to work for the OR salt after some evaluation experiments were performed at the Korea Atomic Energy Research Institute [37]. This difficulty could be partially due to the differences in ionic radii for $\mathrm{Li}^{+}, \mathrm{Na}^{+}$, and $\mathrm{K}^{+}$of 59, 99, and $137 \mathrm{pm}$ (at a coordination number of IV) [38], respectively, where the lower ionic radius of $\mathrm{Li}^{+}$provides some stresses within the crystalline network inhibiting a stable crystalline formation.

$$
\mathrm{Na}_{12}\left(\mathrm{AlSiO}_{4}\right)_{12}+4 \mathrm{LiCl} \stackrel{950^{\circ} \mathrm{C}}{\longrightarrow} 2 \mathrm{Li}_{2} \mathrm{Na}_{6}\left(\mathrm{AlSiO}_{4}\right)_{6} \mathrm{Cl}_{2}
$$

An example of a hydrothermal reaction is presented in Equation (3a). In this approach, the precursors are mixed with water at elevated temperatures $(T)$ and pressures $(P)$, typically within an autoclave. More alkaline solutions tend to yield a higher purity product, but then the disadvantage is that an excess of halide is required to prevent competition of the halide with $\mathrm{OH}^{-}$ in solution. Then, some of the reactants are not consumed, leading to unincorporated waste 
components that would require recycle into subsequent iterations of the same process. The lowtemperature solution-based route is similar to the hydrothermal route but it is run at lower temperatures and at ambient pressure as it is not run in an autoclave - see Equation (3b). The limitation to the lower temperature/pressure approach is that it can be difficult to completely dissolve some of the precursors. In both cases, the salt component is dissolved in solution so this provides good homogeneous distribution for the salt throughout the product.

$$
\begin{gathered}
6 \mathrm{SiO}_{2}+6 \mathrm{NaAlO}_{2}+2 \mathrm{LiCl}+x \mathrm{H}_{2} \mathrm{O} \stackrel{T \sim 150^{\circ} \mathrm{C}, \uparrow P}{\longrightarrow} \mathrm{Li}_{2} \mathrm{Na}_{6}\left(\mathrm{AlSiO}_{4}\right)_{6} \mathrm{Cl}_{2}+x \mathrm{H}_{2} \mathrm{O} \\
6 \mathrm{SiO}_{2}+6 \mathrm{NaAlO}_{2}+2 \mathrm{LiCl}+x \mathrm{H}_{2} \mathrm{O} \stackrel{T \sim 25^{\circ} \mathrm{C}}{\longrightarrow} \mathrm{Li}_{2} \mathrm{Na}_{6}\left(\mathrm{AlSiO}_{4}\right)_{6} \mathrm{Cl}_{2}+x \mathrm{H}_{2} \mathrm{O}
\end{gathered}
$$

The sol-gel approach is more complicated. While this process is similar to other solutionbased processes, it is different because reactants undergo hydrolysis and polycondensation reactions that result in an interlinked network within a solvent matrix. For this, alkoxide solutions such as tetraethyl orthosilicate $\left[\mathrm{Si}\left(\mathrm{OC}_{2} \mathrm{H}_{5}\right)_{4}\right.$ or TEOS] or aluminum-tri-sec-butoxide $\left[\mathrm{Al}\left(\mathrm{OC}_{4} \mathrm{H}_{9}\right)_{3}\right]$ are typically used and mixed with the salts. When TEOS is in the presence of water, it hydrolyses and the ethane group is stripped off, creating a silanol (terminal Si-O-H) and allowing for Si-O-Si interlinkages as shown in Figure 1. The hydrolysis of TEOS has been well studied, especially in the process of making silica-based aerogels in acid- or base-catalyzed reactions [39-43]. The rate of hydrolysis can be controlled by maintaining the level of water added. A hypothetical example sol-gel reaction for making sodalite is presented in Equation (4) using all organic precursors, a simplified $\mathrm{LiCl}$ salt, and co-solvent alcohols that are shown in brackets with their associated organic counterpart.

$$
\begin{aligned}
& \quad\left[6 \mathrm{Si}\left(\mathrm{OC}_{2} \mathrm{H}_{5}\right)_{4}+\alpha \mathrm{C}_{2} \mathrm{H}_{5} \mathrm{OH}\right]+\left[6 \mathrm{Al}\left(\mathrm{OC}_{4} \mathrm{H}_{9}\right)_{3}+\beta \mathrm{C}_{3} \mathrm{H}_{7} \mathrm{OH}\right]+\left[6 \mathrm{NaOCH}_{3}+\gamma \mathrm{CH}_{3} \mathrm{OH}\right]+ \\
& 2 \mathrm{LiCl}+24 \mathrm{H}_{2} \mathrm{O} \rightarrow \mathrm{Li}_{2} \mathrm{Na}_{6}\left(\mathrm{AlSiO}_{4}\right)_{6} \mathrm{Cl}_{2}+(24+\alpha) \mathrm{C}_{2} \mathrm{H}_{5} \mathrm{OH}+18 \mathrm{C}_{4} \mathrm{H}_{9} \mathrm{OH}+(6+\gamma) \mathrm{CH}_{3} \mathrm{OH}+ \\
& \beta \mathrm{C}_{3} \mathrm{H}_{7} \mathrm{OH}
\end{aligned}
$$




\section{EXPERIMENTAL METHODS}

\subsection{Common aspects of sodalite synthesis methods}

All sodalite batches used a simplified OR salt simulant composition that is presented in Table 1 where the fission products include $\mathrm{Ba}, \mathrm{Cs}$, I, and Sr. The concentrations of salts used in the simulant were selected based on solubility limits at room temperature. These values can be further optimized although that was not attempted during the current study. In all cases, the volume of salt simulant solution added was based on a balanced reaction with the other constituents. All of the solution-based methods described here were performed in perfluoroalkoxy Teflon beakers with Teflon-coated stir bars to allow for effective product recovery. The sample naming conventions are listed in Table 2.

\subsection{Aluminum-precursor}

An aluminum source additive was required to balance the alkali:Al molar ratio for the sodalites made with $\mathrm{NaAlO}_{2}$ and $\mathrm{LiAlO}_{2}$ because of the additional $\mathrm{R}^{\mathrm{I}}$ contribution in the OR salt from $\mathrm{Li}_{2} \mathrm{O}$ and also because the alkali aluminates have a fixed alkali:Al ratio. The two candidate precursors for the alumina source were boehmite $[\mathrm{AlO}(\mathrm{OH})$, Nabaltec APYRAL AOH60] and gibbsite $\left[\mathrm{Al}(\mathrm{OH})_{3}\right.$, Almatis $\mathrm{H} 710$ hydrated alumina] based on the results from previous studies $[44,45]$. For comparison purposes, the specific surface areas and particle size distributions were measured.

\subsection{Batching $\mathrm{NaAlO}_{2}$-based sodalites}

For both TEOS and CS approaches, $34.391 \mathrm{~g}$ (0.4196 moles) of $\mathrm{NaAlO}_{2}$ was mixed with $0.493 \mathrm{~g}(0.0082$ moles $)$ of $\mathrm{AlO}(\mathrm{OH})$ in $119 \mathrm{~mL}$ of deionized water (DIW) and heated at $80{ }^{\circ} \mathrm{C}$ for $5 \mathrm{~h}$. The samples made with $\mathrm{CS}$ and $\mathrm{NaAlO}_{2}$ are denoted as CS-SA and the samples made 
with TEOS and $\mathrm{NaAlO}_{2}$ are denoted as TE-SA. Further synthesis details are outlined below.

\subsubsection{Batching sodalite with TEOS, boehmite, $\mathrm{NaAlO}_{2}$, and OR salt simulant}

This section describes the processes unique to the TEOS-based sodalites. First, equal volumes $(95.42 \mathrm{~mL})$ of TEOS and absolute ethanol $(\mathrm{EtOH})$ were mixed together according to the literature [41, 42]. This volume of TEOS corresponds to 0.4278 moles of $\mathrm{SiO}_{2}$ at a $\mathrm{SiO}_{2}$ concentration of 28.84 mass $\%$ and a density of $0.934 \mathrm{~g} / \mathrm{cm}^{3}$. Then, $30 \mathrm{~mL}$ of the OR salt solution (Table 1) was mixed with the TEOS:EtOH solution and the $\mathrm{NaAlO}_{2} / \mathrm{AlO}(\mathrm{OH})$ solution was slowly added to this mixture. At first, the solution turned a deep yellow and, as more of this solution was added to the mixture, the mixture turned white as the viscosity noticeably increased. Within a matter of 10-20 s after the entirety of the solutions were mixed together, the product solidified with a consistency similar to that of thick, wet sand.

\subsubsection{Batching sodalite with $\mathrm{CS}$, boehmite, $\mathrm{NaAlO}_{2}$, and OR salt simulant}

This section describes the processes unique to the CS-based sodalites. In this process, 30 $\mathrm{mL}$ of the OR salt solution (Table 1) was mixed with $49.43 \mathrm{~mL}$ of LUDOX ${ }^{\circledR}$ HS-40 CS (40 mass\% solids, Sigma-Aldrich, St. Louis, $\mathrm{MO})$ and the $\mathrm{NaAlO}_{2} / \mathrm{AlO}(\mathrm{OH})$ solution was added in slowly. This volume of CS corresponds to 0.4278 moles of $\mathrm{SiO}_{2}$ at a density of $1.3 \mathrm{~g} / \mathrm{cm}^{3}$. Once all of the solutions were combined, the viscosity noticeably increased, although not too drastically, and remained as a stable, moderate-viscosity solution. Then, the solution was left to stir for $16 \mathrm{~h}$ to improve the interactions between the precursors.

\subsection{Batching sodalite with organic precursors and $O R$ salt simulant}

In order to evaluate the sol-gel approach to making sodalite, a method was used based solely on organic precursors, the OR salt, and limited water content according to a similar 
process described elsewhere [43]. For this approach, a small-scale batch was made using three separate solutions. For solution (1), $9.54 \mathrm{~mL}$ of TEOS (0.0428 moles $\mathrm{SiO}_{2}$, Sigma Aldrich) was mixed with an equal volume of EtOH according to the literature $[41,42]$ and left to stir in a 100 $\mathrm{mL}$ Teflon beaker. For solution (2), $10.9 \mathrm{~mL}$ of aluminum-tri-sec-butoxide [0.0428 moles Al; $\mathrm{Al}\left(\mathrm{OC}_{4} \mathrm{H}_{9}\right)_{3}$, Sigma Aldrich] was mixed with an equal volume of isopropanol (Sigma Aldrich) in a Teflon bottle within a nitrogen glovebox $\left(\mathrm{O}_{2} / \mathrm{H}_{2} \mathrm{O}<0.1 \mathrm{ppm} ; \mathrm{M}-\mathrm{Braun}\right.$, Inc., Stratham, $\left.\mathrm{NH}\right)$ to prevent hydrolysis, the bottle was capped, and transferred out of the glovebox for use. For solution (3), $3 \mathrm{~mL}$ of the OR salt simulant (Table 1) was mixed with $21.02 \mathrm{~mL}$ of $2 \mathrm{M} \mathrm{C}_{2} \mathrm{H}_{3} \mathrm{NaO}_{2}$ solution (0.0420 moles Na; Sigma Aldrich). Solution (2) was slowly added to solution (1) followed shortly thereafter by the addition of solution (3). The viscosity of the mixture increased rapidly and visibly phase-separated.

\subsection{Batching $\mathrm{LiAlO}_{2}$-based sodalites}

In order to compare the interaction of $\mathrm{Na}$ and $\mathrm{Li}$ with the other precursors, $\mathrm{LiAlO}_{2}$ was evaluated as the alternative alkali aluminate source for $\mathrm{NaAlO}_{2}$ in both the TEOS-based and CSbased processes. This was done to evaluate how the reaction would progress if an excess of $\mathrm{Li}$ was introduced and Na was completely avoided. In this case, $27.658 \mathrm{~g}$ (0.4196 moles) of $\mathrm{LiAlO}_{2}$ was mixed with $0.493 \mathrm{~g}(0.0082$ moles $)$ of $\mathrm{AlO}(\mathrm{OH})$ in $119 \mathrm{~mL}$ of DIW and heated at $80{ }^{\circ} \mathrm{C}$ for

4-6 $\mathrm{h}$ to improve dissolution. The samples made with CS and $\mathrm{LiAlO}_{2}$ are denoted as CS-LA and the samples made with TEOS and $\mathrm{LiAlO}_{2}$ are denoted as TE-LA.

\subsection{Post reaction processing}

\subsubsection{Preparing samples}

Once the solution-based reactions were deemed complete by visual inspection, the Teflon 
stir bars were removed from the beakers and the samples were dried overnight at $90{ }^{\circ} \mathrm{C}$ in an oven. Once dry, the powders were ground in a tungsten carbide mill to homogenize for $0.5 \mathrm{~min}$. Portions of each batch were subsequently calcined at either $500{ }^{\circ} \mathrm{C}$ or $600{ }^{\circ} \mathrm{C}$ for $3 \mathrm{~h}$.

\subsubsection{Preparing the glass binder}

A glass binder (SA800) was added to some of the pellets as a sintering aid described in more detail elsewhere [46] and had a composition of $42.50 \% \mathrm{SiO}_{2}, 34.89 \% \mathrm{Na}_{2} \mathrm{O}$, and $21.62 \%$ $\mathrm{B}_{2} \mathrm{O}_{3}$, by mass. The glass was made by mixing stoichiometric quantities of $\mathrm{SiO}_{2}, \mathrm{Na}_{2} \mathrm{CO}_{3}$, and $\mathrm{H}_{3} \mathrm{BO}_{3}$, milling the powders in an agate mill, melting the glass at $1050{ }^{\circ} \mathrm{C}$ and pouring on an Inconel pour plate to cool. The glass was then powdered in the tungsten carbide mill and added to select batches as a powder at 5 or 10 mass $\%$.

\subsubsection{Preparing pellets for cold-press-and-sinter (CPS)}

Approximately 1-g pellets were made using various preparation techniques from the asmade and as-calcined powders using a cold-press-and-sinter (CPS) method. The pellets made with the as-calcined product were milled for $0.5 \mathrm{~min}$ following the heat-treatment. Others were made by adding enough of the SA800 glass binder to an aliquot from a calcined batch to yield $\sim 1$ $\mathrm{g}$ of total mixture with 5 mass $\%$ or 10 mass $\%$ glass binder, which was subsequently milled for either 0.5 or 4 min (samples with a 4-min mill time were denoted with an additional "-M-"). All mixtures were uniaxially pressed into pellets at $8.5 \times 10^{7} \mathrm{~Pa}$ and fired at $750{ }^{\circ} \mathrm{C}$ for $8 \mathrm{~h}$. After firing, the pellets were broken into quadrants for characterization.

\subsubsection{Hot uniaxial pressing (HUP)}

Hot uniaxial pressing (HUP) was evaluated as an alternative consolidation method to the CPS method for CS-SA and TE-SA samples and the samples designations include a "HUP" 
suffix. The samples evaluated with this method included: TE-SA-CA(600)-5GB-M-HUP, TESA-CA(600)-10GB-M-HUP，CS-SA-CA(600)-5GB-M-HUP， and CS-SA-CA(600)-10GB-MHUP. The apparatus used to prepare these samples is described elsewhere in detail [47]. Here, a small amount of powdered mixture $(\sim 0.082-0.087 \mathrm{~g})$ containing the specimen and added glass binder was loaded into an alumina crucible $(9.55 \mathrm{~mm}$ outer- $\varnothing, 6.42 \mathrm{~mm}$ inner- $\varnothing, 19 \mathrm{~mm}$ tall $)$ and an alumina disc $(5.8 \mathrm{~mm} \varnothing, 0.3 \mathrm{~mm}$ thick) was added to the top of the powder. Then, the crucible was inserted into a furnace at $750{ }^{\circ} \mathrm{C}$ and under a uniaxial pressure of $29 \mathrm{MPa}$ using a push rod with compressed air against a mullite stage. After $30 \mathrm{~min}$, the push rod was retracted from the furnace and then the crucible was removed and air quenched for further analysis.

\subsection{Specimen characterization}

Samples and specimens were characterized with X-ray diffraction (XRD), scanning electron microscopy (SEM), energy dispersive spectroscopy (EDS), and specific surface area using the techniques described elsewhere [9]. Additional characterizations are described below.

\subsubsection{Density and porosity}

The volume and mass of pre- and post-fired pellets were measured using digital calipers and an analytical balance, respectively, so the bulk densities $\left(\rho_{\mathrm{b}}\right)$ could be calculated. The theoretical densities $\left(\rho_{\mathrm{t}}\right)$ of fired pellets were calculated with Equation (5) using the mass fraction $\left(m_{i}\right)$ of each phase (determined with XRD) and the known densities for those phases $\left(\rho_{i}\right)$ found in the crystallographic information files (CIFs) from the International Crystal Structure Database. The difference in percent is considered the porosity of the fired pellet where if a pellet was determined to have $80 \%$ of $\rho_{\mathrm{t}}$, it contains $20 \%$ total porosity $\left(\phi_{\mathrm{t}}\right)$, by volume - see Equations (6) and (7). 


$$
\begin{gathered}
\rho_{\mathrm{t}}=\sum_{i=1}^{n} \rho_{i} m_{i} \\
\% \text { of } \rho_{\mathrm{t}}=100 *\left(\rho_{\mathrm{b}} / \rho_{\mathrm{t}}\right) \\
\phi_{\mathrm{t}}=100-\left[100 *\left(\rho_{\mathrm{b}} / \rho_{\mathrm{t}}\right)\right]
\end{gathered}
$$

For some specimens, the density was determined on fired pellets with an AccuPyc II 1340 pycnometer $\left(\rho_{\mathrm{p}}\right)$ (Micromeritics Instrument Corporation, Norcross, GA). Specimen masses were recorded on an analytical balance to the nearest $0.1 \mathrm{mg}$ and volumes were calculated as the average of 10 purge-fill cycles using ultra high purity He gas so pycnometer density $\left(\rho_{\mathrm{p}}\right)$ could be calculated. These data were used as a comparison to the $\rho_{\mathrm{t}}$ calculated using Equation (5). The volume of closed porosity, $\phi_{\mathrm{c}}$, could be estimated based on the difference between the $\rho_{\mathrm{b}}$ and the $\rho_{\mathrm{p}}$ values for the fired pellets that were measured with the pycnometer.

\subsubsection{Particle size distribution}

The particle size distribution (PSD) was measured for select precursors and specimens. This technique was used to evaluate PSD as a function of milling time $(t=0.5,1,2$, and 4 min) for a series of specimens. These were evaluated in aqueous mixtures with a Malvern MS 2000 and a Hydro G accessory (Malvern Instruments Ltd., United Kingdom) as unsonicated, sonicated, and after sonication. The sonicated data were used for comparison purposes.

\section{RESULTS AND DISCUSSION}

\subsection{Alumina precursor}

The $\mathrm{AlO}(\mathrm{OH})$ was selected as the Al-source from the two candidate alumina sources for use with the solution-based processes based on the smaller particle size (Figure 2) and a marginally higher specific surface area of $5.4 \mathrm{~m}^{2} / \mathrm{g}$ over that of $3.5 \mathrm{~m}^{2} / \mathrm{g}$ measured for $\mathrm{Al}(\mathrm{OH})_{3}$. The particle size distributions for the two different chemicals were significantly different. The 
$\mathrm{Al}(\mathrm{OH})_{3}$ was monodispersed with a unimodal distribution centered around $3 \mu \mathrm{m}$. The $\mathrm{AlO}(\mathrm{OH})$ had a larger particle size range with a trimodal distribution (with maxima at $\sim 0.12, \sim 1.2$, and $\sim 12 \mu \mathrm{m})$. For the $\mathrm{Al}(\mathrm{OH})_{3}$, the size range was $\sim 1-10 \mu \mathrm{m}$ whereas the $\mathrm{AlO}(\mathrm{OH})$ had a larger particle size range from $\sim 0.04-30 \mu \mathrm{m}$ with a majority of the particles being $<1.2 \mu \mathrm{m}$ in size. Based on the lower particle size measured for the boehmite and despite the larger sized fraction, this candidate was selected for the current study with the prediction that the smaller particles would be more reactive with the other precursors. However, this particular gibbsite might be a promising candidate for future work because of its narrow particle size distribution.

\section{2 $\mathrm{NaAlO}_{2}$-based sodalites}

Figure 3 shows the XRD spectra for the TE-SA-AM and CS-SA-AM samples. The asmade TE-SA sample contained $\mathrm{NaCl}$ and $\mathrm{Al}(\mathrm{OH})_{3}$ as primary phases with $\mathrm{AlO}(\mathrm{OH})$ and $\mathrm{LiAl}_{2}(\mathrm{OH})_{7} \cdot x \mathrm{H}_{2} \mathrm{O}$ as minor phases. The CS-SA contained $\mathrm{NaCl}$ and $\mathrm{LiAl}_{2}(\mathrm{OH})_{7} \cdot x \mathrm{H}_{2} \mathrm{O}$. Both the TE-SA and CS-SA samples contained some portion of nanostructured product denoted by the broad diffraction peaks (humps).

The phase analysis results for the $\mathrm{NaAlO}_{2}$-based pellets fabricated under different conditions are presented in Table 3. For each of the specimens, all peaks were identified and quantified using Rietveld refinements. The amorphous content was difficult to quantify based on the small sample sizes and is not presented here.

Examples of fitted XRD patterns are shown in Figure 4 for TE-SA and CS-SA specimens without a glass binder (Figure 4a and b, respectively) and those with 10 mass\% SA800 that were milled for 4 min (Figure $4 c$ and d, respectively). In all cases, lithium silicates (e.g., $\mathrm{Li}_{2} \mathrm{SiO}_{3}$ or $\mathrm{Li}_{2} \mathrm{Si}_{2} \mathrm{O}_{5}$ ) were observed (7.8-11.4 mass\%), providing evidence of a fast reaction between free $\mathrm{SiO}_{2}$ and $\mathrm{Li}_{2} \mathrm{O}$ in solution before the sodalite was formed. It should be noted that no unreacted 
salts were observed in any of the specimens that were cold-pressed-and-sintered, which was not universally the case in a previous sodalite study with the $\mathrm{LiCl}-\mathrm{KCl}$ eutectic salt [9]. However, some unreacted $\mathrm{NaCl}$ was observed in all of the specimens that were prepared with HUP (Table 3).

Several of the experimental variables showed evidence of improved sodalite yield and densification (reduced open porosity). First, the results show that the glass binder additions noticeably improved the sodalite yield in the progression of $0 \rightarrow 5 \rightarrow 10$ mass $\%$ and reduced the nepheline fraction, which was expected based on a previous study [9]. Second, the densities of the fired pellets that were milled for shorter times $(0.5 \mathrm{~min})$ were notably lower by $7.4-15.3 \%$ than those subjected to longer milling times $(4 \mathrm{~min})$ when all other variables were held constant demonstrating the benefit of effective mixing prior to firing.

Figure 5 provides the PSD results for various CS-SA and TE-SA formulations that were mixed for different times and not fired. For comparison, the as-made samples were included as well as specimens both with and without 10 mass\% SA800 glass binder (both calcined at $600{ }^{\circ} \mathrm{C}$ ). These results show that the PSD markedly decreased from the as-made material and continued to decrease with longer milling times. It is postulated that the smaller particles interacted with the glass binder more effectively to aid in closing the porosity. When comparing the plots in Figure 5b, it is apparent that, when subjected to equal milling times, adding a glass binder did not have much of an effect on the PSD, which was expected.

The results in Figure 6 show the progression of densification improvements for CS-SA formulations where the $\%$ of $\rho_{\mathrm{t}}$ steadily increased within the series of specimens that (1) were calcined at $600{ }^{\circ} \mathrm{C}$ and fired at $750{ }^{\circ} \mathrm{C} \rightarrow$ (2) had 5\% SA800 added and fired at $750{ }^{\circ} \mathrm{C} \rightarrow$ (3) had $5 \%$ SA800 added and were milled for 4 min (versus $0.5 \mathrm{~min}$ ) and fired at $750{ }^{\circ} \mathrm{C} \rightarrow(4)$ had 
$10 \%$ SA800 added and were milled for 4 min and fired at $750{ }^{\circ} \mathrm{C} \rightarrow(5)$ had $10 \%$ SA800 added and were milled for $4 \mathrm{~min}$ and consolidated with hot uniaxial pressing. While the densification progressively improved over these last three, i.e., (2)-(5), the sodalite yield remained relatively constant (Table 3). The increased milling time had a large effect on closing the porosity and this is attributed to, at least partially, the smaller particle sizes (Figure 5). Also, it is worth noting that calcining at $500{ }^{\circ} \mathrm{C}$ versus $600{ }^{\circ} \mathrm{C}$ did not appear to make a noticeable difference in the sodalite yield; rather, the phase distributions between the different sets of specimens were even identical in one case.

The SEM collage presented in Figure 7 shows the differences in microstructure and bulk porosity between a subset of the TE-SA and CS-SA specimens. The microstructure in both specimens without glass binders showed a high degree of heterogeneity and porosity while the progression of added glass binder and longer milling times gradually reduced the porosity within the specimens. This progression is better highlighted in Figure 8 for the CS-SA specimens under various conditions at a higher magnification with the least porous being the HUP specimen with 10 mass\% GB (CS-SA-CA600-10GB-M-HUP). However, the trade-off with this particular HUP specimen, while providing the result of lower porosity, is that it did still contain unreacted $\mathrm{NaCl}_{2}$ denoted by the bright spots in Figure 8d. The higher magnification SEM micrographs in Figure

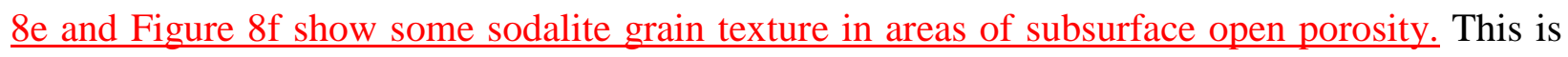
likely due to the lower reaction time used for the HUP specimens (30 $\mathrm{min}$ ) as opposed to the 8-h heat-treatment time used with the CPS specimens. The CS-SA-CA(600)-10GB-M-HUP specimen showed very low open porosity ( $<5$ vol $\%$ ) based on Figure 8 and the calculated $\%$ of $\rho_{\mathrm{t}}$ was $100.4 \%$ (Figure 6), despite small visible pores (thus the actual porosity was not 0 vol\%). The discrepancy here was attributed to errors associated with the volume measurements of the HUP 
specimens. These results demonstrate the improvement that HUP provides over the CPS method.

Figure 9 provides a comparison between the densities measured with the pycnometer $\left(\rho_{\mathrm{p}}\right)$ and the $\rho_{\mathrm{t}}$ values calculated with Equation (5) for select TE-SA and CS-SA specimens. This shows a clear trend with both sets of samples where the density decreases with increasing glass binder. Since the crystalline phases have known densities and the SA800 glass has a starting density of $2.551 \mathrm{~g} / \mathrm{cm}^{3}$, the density should not decrease with added binder but, rather it should increase. This steady decrease in $\rho_{\mathrm{p}}$ values for both TE-SA and CS-SA specimens is attributed to closed porosity that was inaccessible during the pycnometry measurements for the pellets with increasing fractions of glass binders; this resulted in artificially inflated volume values leading to lower densities values.

\section{3 $\mathrm{LiAlO}_{2}$-based process}

For the $\mathrm{LiAlO}_{2}$-based process, when the $\mathrm{LiAlO}_{2}$ and $\mathrm{AlO}(\mathrm{OH})$ were combined with DIW, a fine white powder remained in solution that settled when the stirring was paused. The $\mathrm{LiAlO}_{2}$ did not noticeably dissolve in the water even after heating at $80{ }^{\circ} \mathrm{C}$ for $5 \mathrm{~h}$. When all of the solutions were combined, the viscosity did not noticeably change suggesting that at least some of the constituents had prereacted while in their individual solutions prior to mixing or the different solutions had minimal interactions. The XRD results on the as-made material showed high fractions of $\mathrm{LiAlO}_{2}$ and $\mathrm{LiCl}\left(\mathrm{H}_{2} \mathrm{O}\right)$, as well as other phases of $\left(\mathrm{Al}_{2} \mathrm{O}_{3}\right)_{5.3}, \mathrm{LiAl}_{5} \mathrm{O}_{8}$, and $\mathrm{AlO}(\mathrm{OH})$ suggesting that little interactions took place between the precursors and that the silica was likely present in the powder as nano-sized $\mathrm{SiO}_{2}$ particles since no diffraction peaks were observed with XRD.

The phase distribution after calcination showed high fractions of unincorporated $\mathrm{LiAlO}_{2}$, $\mathrm{LiAl}_{5} \mathrm{O}_{8}$, and $\mathrm{LiCl}\left(\mathrm{H}_{2} \mathrm{O}\right)$ present in the specimens. Once fired at $750{ }^{\circ} \mathrm{C}$, sodalite was only 
observed in CS-LA-CA(600)-5GB-750 and was present at a very low concentration of 8.9 mass\%. Additionally, $\mathrm{LiAlO}_{2}, \mathrm{LiAlSiO}_{4}, \mathrm{LiAlSi}_{2} \mathrm{O}_{6}, \mathrm{LiAl}_{5} \mathrm{O}_{8}, \mathrm{Li}_{2} \mathrm{SiO}_{3}, \mathrm{Li}_{2} \mathrm{Si}_{2} \mathrm{O}_{5}$, and various forms of $\mathrm{SiO}_{2}$ as well as a few other minor phases were observed. This provides evidence that the lack of precursor interactions during the solution-based synthesis steps were not improved during the calcination or firing processes outlining the need for better initial mixing during the synthesis process. Thus, this process was not pursued further but could warrant further attention if a different approach were taken such as a hydrothermal processing route where higher temperatures and pressures might assist with the dissolution of these precursors.

\subsection{Sodalite with organic precursors and OR salt simulant}

The goal of using organic precursors was to allow for more controlled intermixing. It was expected that the organic content from the constituents used to make these samples would evolve during drying by evaporation or during calcination by burn-off. The XRD spectrum of the asmade powder showed some broad amorphous diffraction peaks and sharp diffraction peaks for unincorporated $\mathrm{NaCl}$ and $\mathrm{C}_{2} \mathrm{H}_{3} \mathrm{NaO}_{2}$. After calcination at $600{ }^{\circ} \mathrm{C}$ for $3 \mathrm{~h}, \mathrm{NaCl}$ was still present along with a small fraction of $\mathrm{Na}_{1.65} \mathrm{Al}_{1.65} \mathrm{Si}_{0.35} \mathrm{O}_{4}$. The specimen fired at $750{ }^{\circ} \mathrm{C}$ for $8 \mathrm{~h}$ without the glass binder contained a mixture of $\mathrm{NaCl}, \mathrm{LiAlO}_{2}$, and $\mathrm{Na}_{1.75} \mathrm{Al}_{1.75} \mathrm{Si}_{0.25} \mathrm{O}_{4}$. The specimens mixed with 5 or 10 mass $\%$ glass binder and fired at $750{ }^{\circ} \mathrm{C}$ for $8 \mathrm{~h}$ had sodalite $\left.\left[\mathrm{Na}_{8}\left(\mathrm{AlSiO}_{4}\right)_{6} \mathrm{Cl}_{2}\right)\right], \mathrm{NaCl}, \mathrm{LiAlO}_{2}, \mathrm{Na}_{6} \mathrm{Al}_{4} \mathrm{Si}_{4} \mathrm{O}_{17}$, and an unidentified majority phase. While this approach formed sodalite, the fractions were not substantial. It is possible that alternative forms of sodium might provide a more effective mixing process and lead to less unincorporated reactant such as a sodium alkoxide (e.g., $\mathrm{NaOCH}_{3}, \mathrm{NaOC}_{2} \mathrm{H}_{5}$ ) but these were not investigated within the scope of the current study because these alkoxides are less compatible with water, which is required for hydrolysis. 


\subsection{Implications of this study and areas of needed improvement}

It is possible to incorporate $\mathrm{Li}^{+}$into Na-sodalite with a high-temperature ion exchange process according to the literature [17-20]. However, this The-high temperature ion exchange method-approach reported in the literature - does not seem plausible for the OR salt as it would likely evolve the volatile fission products from the waste (e.g., Cs, I) and $\mathrm{Li}^{+}$would have to compete for the alkali sites occupied by $\mathrm{Na}^{+}$. In the current study, the moderate fractions of lithium silicates found in the fired pellets and the uncertainty in determining the amorphous fraction provided evidence of low $\mathrm{Li}^{+}$incorporation into the sodalite. This was attributed to a fast reaction between the free $\mathrm{Na}^{+}$and $\mathrm{Cl}^{-}$that preferentially integrated into the sodalite.

The results from this study and those communicated by Cho and Park [37] for the hightemperature structural conversion method demonstrate that making sodalite with the OR salt might prove difficult without the formation of secondary phases. The secondary phases observed in this study are-were lithium silicates (e.g., $\mathrm{Li}_{2} \mathrm{SiO}_{3}$ and $\mathrm{Li}_{2} \mathrm{Si}_{2} \mathrm{O}_{5}$ ) and unreacted $\mathrm{NaCl}$, none of which are considered to have high chemical durability. However, this might not prove to be a completely detrimental issue if these phases do not contain any fission products and are not present in an interconnective network throughout the waste form.

The hish temperatue

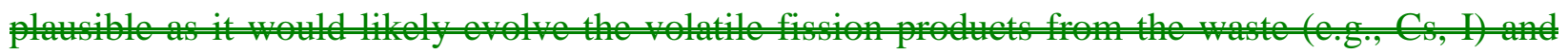
$\mathrm{Ei}^{+}$-uld have to compete for the allalis sites oecupied by $\mathrm{Na}^{+}=$

Additionally, the SA800 glass binder was not optimized for this particular composition of sodalite so compositional adjustments could be made to this binder in an attempt to improve the densification potential. Alternative sintering options not evaluated in this study include hot isostatic pressing or spark plasma sintering that could further improve the densification and 
possibly reduce the secondary (unwanted) phases in the fired specimens. Finally, the chemical durability of sodalite specimens made with the OR salt will need to be evaluated.

\section{CONCLUSIONS}

Various solution-based processing methods for forming sodalite with an oxide reduction salt were evaluated in this study using a wide range of starting materials. The results from this study reveal that sodalite can be made with the oxide reduction salt $\left(\mathrm{LiCl}-\mathrm{Li}_{2} \mathrm{O}\right), \mathrm{NaAlO}_{2}$, boehmite $[\mathrm{AlO}(\mathrm{OH})]$, and a silica source (TEOS or CS), albeit with small fractions of side reaction phases, e.g., nepheline, lithium silicates (e.g., $\mathrm{Li}_{2} \mathrm{SiO}_{3}$ and $\mathrm{Li}_{2} \mathrm{Si}_{2} \mathrm{O}_{5}$ ), $\mathrm{NaCl}$, and/or $\mathrm{SiO}_{2}$. While it is possible to incorporate $\mathrm{Li}^{+}$into sodalite according to the literature using high temperature ion exchange, this was not demonstrated in the current study where tThe fractions of lithium silicates in the fired pellets were higher than desired providing evidence of low (or zero) $\mathrm{Li}^{+}$incorporation into the sodalite. This was attributed to -after-a fast reaction between the free $\mathrm{Na}^{+}$and $\mathrm{Cl}^{-}$that preferentially integrated into the sodalite.

The TEOS-based sodalites showed higher sodalite fractions ( 88 mass\%) in the specimens without glass binders as opposed to the CS-based sodalites (63-67 mass\%) but the sodalite fraction in the crystalline product from the glass-bonded sodalites were all very similar (90.3-92.1 mass\%) despite the differences in processing variables. The porosities of the pellets fired with 5 mass\% glass binder were higher than desired, compared to previous studies. While most of the pellets showed high porosity, the CS-SA pellets with increased milling times and the highest glass binder loadings (10 mass \%) showed noticeable improvements in lowering the porosity over those with lower milling times and the specimens with 5 mass $\%$ glass binder. The CS-SA specimen that was consolidated with HUP showed a high sodalite fraction (90.1 mass\%) with the lowest calculated porosity of all the specimens. Alternative routes included an attempt 
to make sodalite without sodium (using $\mathrm{LiAlO}_{2}$ as the primary alkali aluminate source) and a method utilizing organic precursors that both proved largely unsuccessful. Using $\mathrm{LiAlO}_{2}$ to replace $\mathrm{NaAlO}_{2}$ might prove more effective in a hydrothermal environment and warrants further attention.

Overall, the solution-based, glass-bonded sodalite synthesis processes described here provide a potential route for immobilizing the OR salts. It is unlikely that the fission products partition into the chemically non-durable secondary phases, so it is possible that they will not affect the overall chemical durability of the final waste form.

\section{ACKNOWLEDGEMENTS}

The Pacific Northwest National Laboratory is operated by Battelle under Contract Number DE-AC05-76RL01830. The authors would also like to express thanks to the U.S. Department of Energy Office of Nuclear Energy Fuel Cycle Research and Development staff and leadership that funded and provided oversight to this work that include K. Bateman, K. Marsden, and M. Goff. Authors would also like to express thanks for assistance from X. Li for help with BET measurements; J. McCloy, J. Crum, and J. Westsik for helpful comments on the manuscript; and C. Chamberlin and S. Carlson for help with cutting and polishing specimens.

\section{REFERENCES}

[1] E.-Y. Choi, J.-M. Hur, I.-K. Choi, S.G. Kwon, D.-S. Kang, S.S. Hong, H.-S. Shin, M.A. Yoo, S.M. Jeong, J. Nucl. Mater. 418 (1-3) (2011) 87-92.

[2] E.-Y. Choi, J.W. Lee, J.J. Park, J.-M. Hur, J.-K. Kim, K.Y. Jung, S.M. Jeong, Chem. Eng. J. 207-208 (2012) 514-520.

[3] S.D. Herrmann, S.X. Li, M.F. Simpson, S. Phongikaroon, Sep. Sci. Technol. 41 (10) (2006) 1965-1983. 
[4] S.M. Jeong, S.B. Park, S.S. Hong, C.S. Seo, S.W. Park, J. Radioanal. Nucl. Chem. 268 (2) (2006) 349-356.

[5] Y. Sakamura, J. Nucl. Mater. 412 (1) (2011) 177-183.

[6] Y. Sakamura, M. Kurata, T. Inoue, J. Electrochem. Soc. 153 (3) (2006) D31-D39.

[7] D.S.M. Vishnu, N. Sanil, N. Murugesan, L. Shakila, C. Ramesh, K.S. Mohandas, K. Nagarajan, J. Nucl. Mater. 427 (1-3) (2012) 200-208.

[8] J.-M. Hur, C.-S. Seo, S.-S. Hong, D.-S. Kang, S.-W. Park, pp. 355-361, Proc. of Progress in Partitioning and Waste forms, 2002.

[9] W.C. Lepry, B.J. Riley, J.V. Crum, C.P. Rodriguez, D.A. Pierce, J. Nucl. Mater. 442 (1-3) (2013) 350-359.

[10] C.M.B. Henderson, D. Taylor, Spectrochim. Acta 33A (1977) 283-290.

[11] M.E. Brenchley, M.T. Weller, Zeolites 14 (8) (1994) 682-686.

[12] T.E. Gier, W.T.A. Harrison, G.D. Stucky, Angen. Chem. Inr. Ed. Engl. 30 (9) (1991) 1169.

[13] W.T.A. Harrison, T.E. Gier, G.D. Stucky, Acta Cryst. 50 (1994) 471-473.

[14] G.M. Johnson, M.T. Weller, Inorg. Chem. 38 (1999) 2442-2450.

[15] G. Kelemen, W. Lortz, G. Schon, J. Mater. Sci. 24 (1) (1989) 333-338.

[16] R. Navarrete-Casas, A. Navarrete-Guijosa, C. Valenzuela-Calahorro, J.D. López-González, A. García-Rodríguez, J. Colloid Interface Sci. 306 (2) (2007) 345-353.

[17] J.M. Newsam, J. Phys. Chem. 91 (5) (1987) 1259-1262.

[18] D. Taylor, Contrib. Mineral. Petrol. 51 (1975) 39-47.

[19] M.T. Weller, G. Wong, Solid State Ionics 32-33 (1) (1989) 430-435.

[20] E.R. Williams, A. Simmonds, J.A. Armstrong, M.T. Weller, J. Mater. Chem. 20 (2010) 10883-10887. 
[21] S. Frank, T. Barber, M. Lambregts, Powder Diff. 20 (3) (2005) 212-214.

[22] H. Babad, D.M. Strachan, "Method for immobilizing radioactive iodine," patent application 4229317, 1980.

[23] B.J. Riley, M.J. Schweiger, D.-S. Kim, W.W. Lukens Jr, B.D. Williams, C. Iovin, C.P. Rodriguez, N.R. Overman, M.E. Bowden, D.R. Dixon, J.V. Crum, J.S. McCloy, A.A. Kruger, J. Nucl. Mater. 452 (1-3) (2014) 178-188.

[24] E. Maddrell, A. Gandy, M. Stennett, J. Nucl. Mater. 449 (1-3) (2014) 168-172.

[25] M.T. Weller, G. Wong, Eur. J. Solid State Inorg. Chem. 26 (6) (1989) 619-633.

[26] T. Nakazawa, H. Kato, K. Okada, S. Ueta, M. Mihara, pp. 51-57, Proc. of Sci. Basis Nucl. Waste Manag. XXIV, 663. Edited y K. P. Hart and G. R. Lumpkin. Materials Research Society. Warrendale, PA, 2001.

[27] S. Frank. 2012. Characterization of Echem Off-Gas Partitioning. FCRD-PAC-2013-000052. Idaho National Laboratory, Idaho Falls, ID.

[28] K.J. Bateman, C.J. Knight, C.W. Solbrig. 2007. Current Status of Ceramic Waste Form Development. INL/INT-06-11736, Rev. 1. Idaho National Laboratory, Idaho Falls, ID.

[29] W.L. Ebert. 2005. Testing to Evaluate the Suitability of Waste Forms Developed for Electrometallurgically-Treated Spend Sodium-Bonded Nuclear Fuel for Disposal in the Yucca Mountain Repository. ANL-05/43. Argonne National Laboratory-East, Argonne, IL.

[30] M.C. Morrison, K.J. Bateman, M.F. Simpson, pp. INL/CON-10-19439, Proc. of International Pyroprocessing Research Conference, 42, 2010.

[31] M.F. Simpson, M.N. Patterson, J. Lee, Y. Wang, J. Versey, S. Phongikaroon, pp. INL/CON13-28041-21044-21049, Proc. of Global 2013, 2013. 
[32] T. Fazal, "High temperature studies of sodalites," MRes, Materials Chemistry and Nanochemistry Thesis, University of Birmingham, 2011.

[33] H. Trill, H. Eckert, V.I. Srdanov, J. Phys. Chem. B. 107 (34) (2003) 8779-8788.

[34] A. Stein, G.A. Ozin, P.M. Macdonald, G.D. Stucky, R. Jelinek, J. Am. Chem. Soc. 114 (13) (1992) 5171-5186.

[35] B.J. Riley, J.V. Crum, J. Matyáš, J.S. McCloy, W.C. Lepry, J. Am. Ceram. Soc. 95 (10) (2012) 3115-3123.

[36] E.R. Vance, J. Davis, K. Olufson, I. Chironi, I. Karatchevtseva, I. Farnan, J. Nucl. Mater. 420 (1-3) (2012) 396-404.

[37] H.-S. Park, Y.-Z. Cho, personal correspondence, 2014.

[38] R.D. Shannon, Acta Cryst. A 32 (1976) 751-767.

[39] C.J. Brinker, K.D. Keefer, D.W. Schaefer, C.S. Ashley, J. Non-Cryst. Solids 48 (1982) 4764.

[40] C.J. Brinker, K.D. Keefer, D.W. Schaefer, R.A. Assink, B.D. Kay, C.S. Ashley, J. NonCryst. Solids 63 (1984) 45-59.

[41] I.M. Thomas, "Method for producing glass precursor compositions and glass compositions therefrom," patent application number 3799754, 1974.

[42] L. Levene, I.M. Thomas, "Process of converting metalorganic componds and high purity products obtained therefrom," patent application number 3640993, 1972.

[43] C.J. Brinker, S.P. Mukherjee, J. Mater. Sci. 16 (7) (1981) 1980-1988.

[44] R.L. Russell, H.D. Smith, D.E. Rinehart, R.A. Peterson. 2009. Development and characterization of gibbsite component simulant. PNNL-18013, WTP-RPT-176. Pacific Northwest National Laboratory, Richland, WA. 
[45] R.L. Russell, R.A. Peterson, H.D. Smith, D.E. Rinehart, P.M. Aker, E.C. Buck. 2009. Development and characterization of boehmite component simulant. PNNL-18176, Rev. 1; WTP-RPT-184, Rev. 1. Pacific Northwest National Laboratory, Richland, WA.

[46] B.J. Riley, J.S. McCloy, J.V. Crum, W.C. Lepry, C.P. Rodriguez, C.F. Windisch Jr., J. Matyáš, M.P. Westman, B.T. Rieck, J.B. Lang, M.J. Olszta, D.A. Pierce. 2014. Alternative Electrochemical Salt Waste Forms, Summary of FY11-FY12 Results. FCRDSWF-2013-000025, Rev.1, PNNL-22034. Pacific Northwest National Laboratory, Richland, WA.

[47] J. Matyáš, M.J. Robinson, G.E. Fryxell, "The Effect of Temperature and Uniaxial Pressure on the Densification Behavior of Silica Aerogel Granules," pp. 121-132. In Ceramic Materials for Energy Applications II, Vol. 33. Edited by K. Fox, Y. Katoh, H.-T. Lin, I. Belharouak, M. Halbig, and S. Mathur. John Wiley \& Sons, Inc., 2012. 


\section{$\underline{\text { Figures }}$}

Tetraethyl orthosilicate (TEOS)

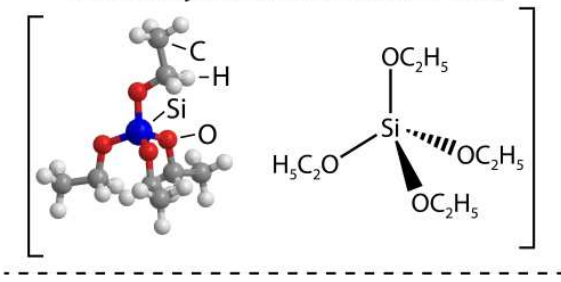

Partial hydrolysis
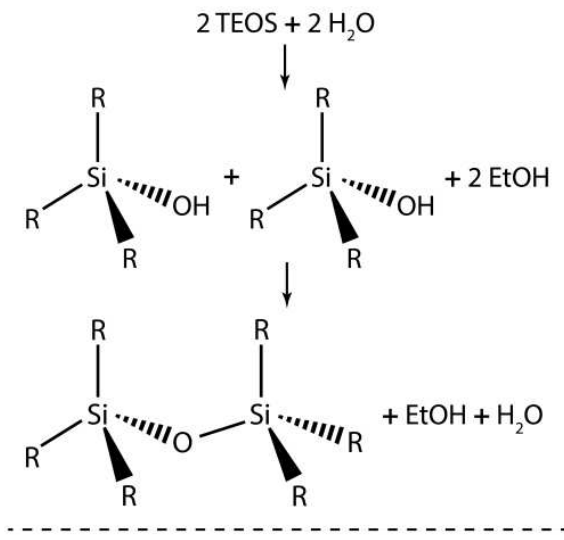

Full hydrolysis

(a)

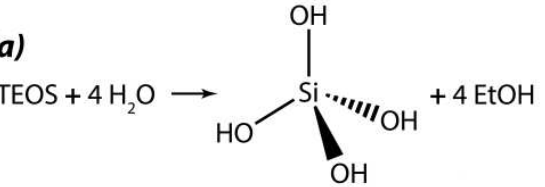

(b)

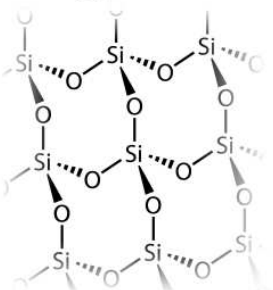

Figure 1. Full and partial hydrolysis of tetraethyl orthosilicate (TEOS; $\mathrm{R}=\mathrm{OC}_{2} \mathrm{H}_{5}{ }^{-}, \mathrm{EtOH}$ = ethanol). 


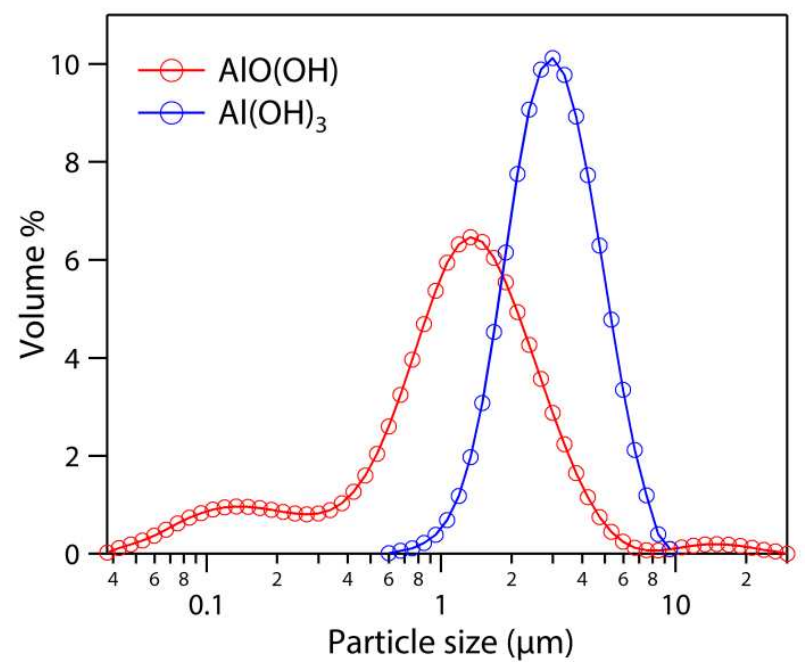

Figure 2. Comparison between $\mathrm{AlO}(\mathrm{OH})$ and $\mathrm{Al}(\mathrm{OH})_{3}$ sources that were evaluated.

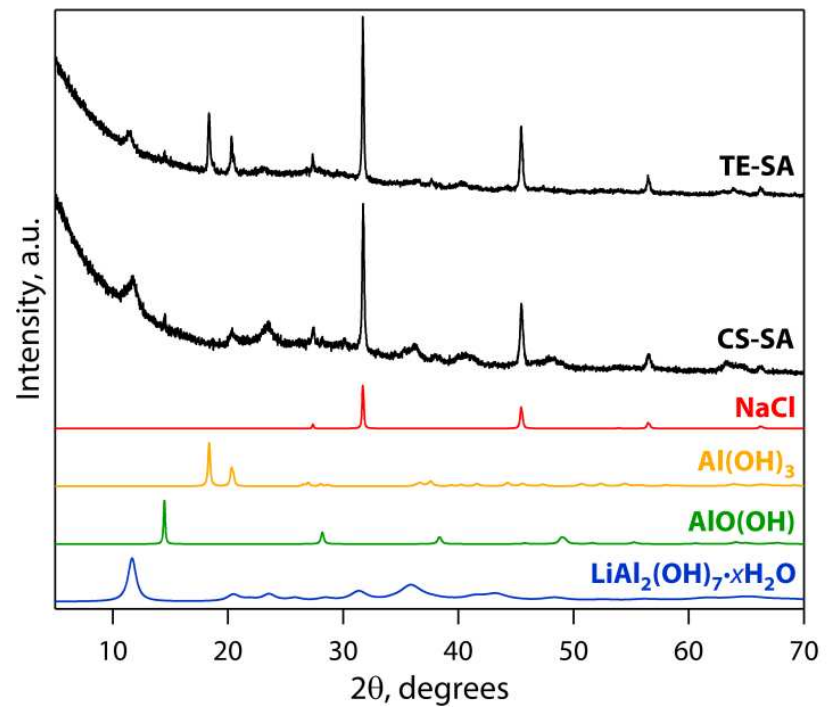

Figure 3. XRD diffraction patterns and fitted phases for TE-SA-AM and SC-SA-AM. 


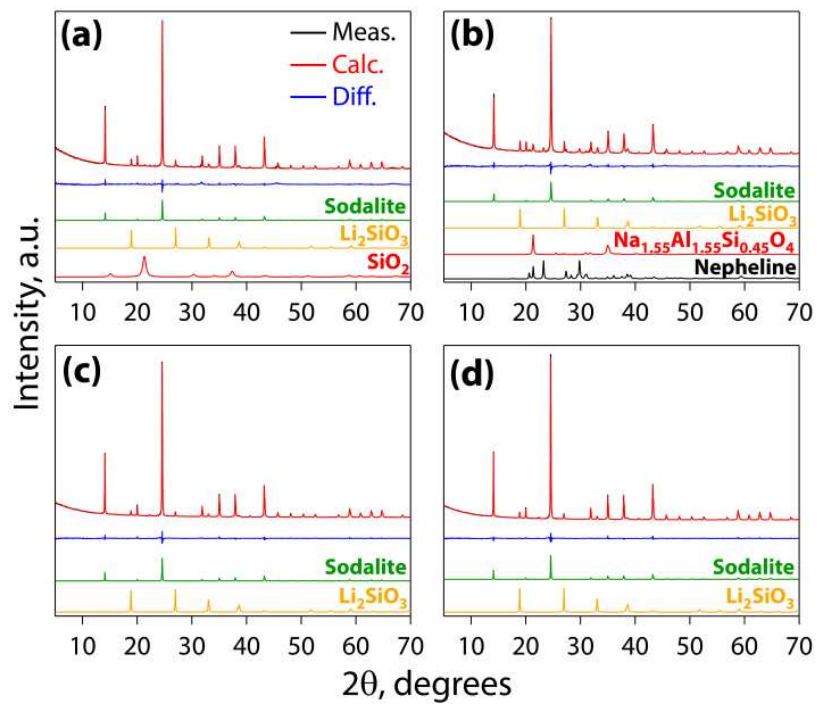

Figure 4. Rietveld refinements for a) TE-SA-CA600-750, b) CS-SA-CA600-750, c) TE-SA-CA600-10GB-M-750, and d) CS-SA-CA600-10GB-M-750.
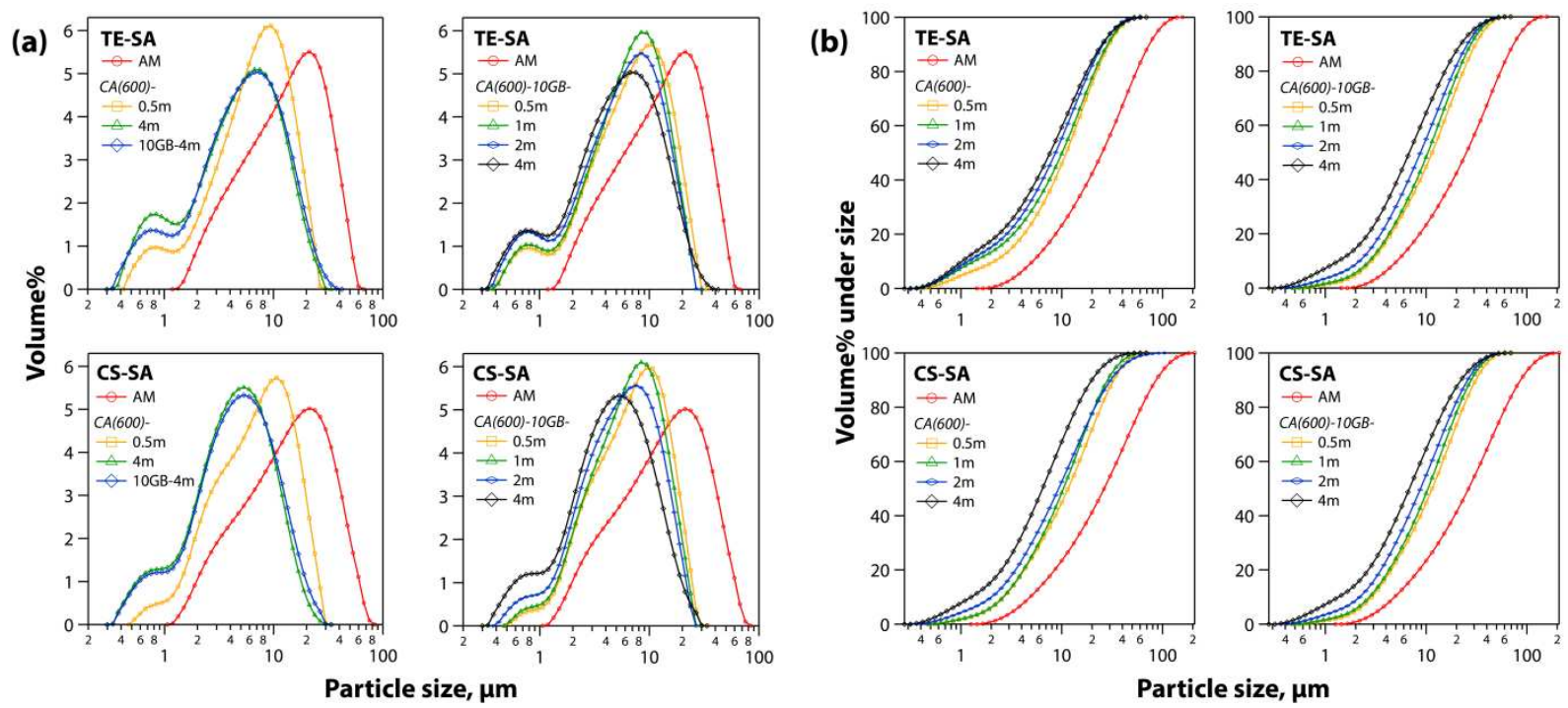

Figure 5. (a) Volume \% and (b) volume \% under size as functions of particle size for various specimens milled for different times (e.g., $0.5,1,2$, and $4 \mathrm{~min}$ ). 


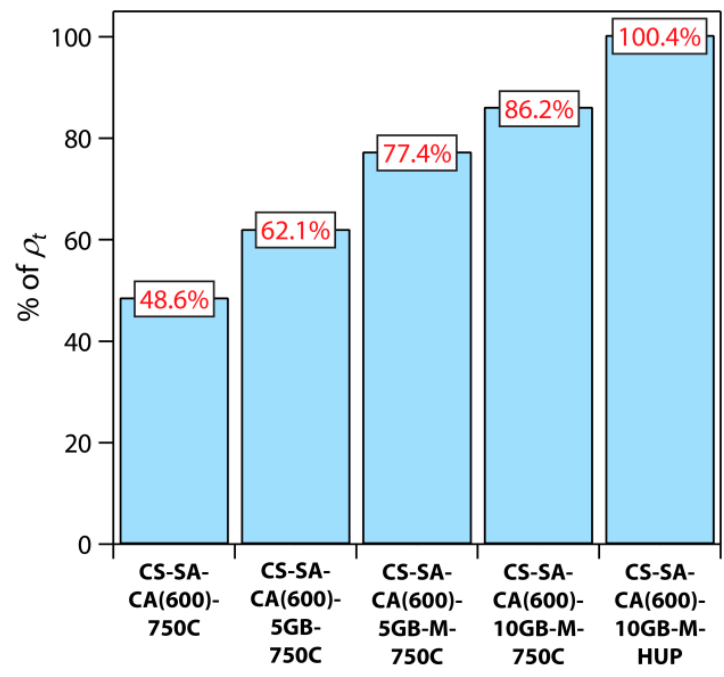

Figure 6. Comparison of density (i.e., porosity) in CS-SA specimens under different processing variables. 

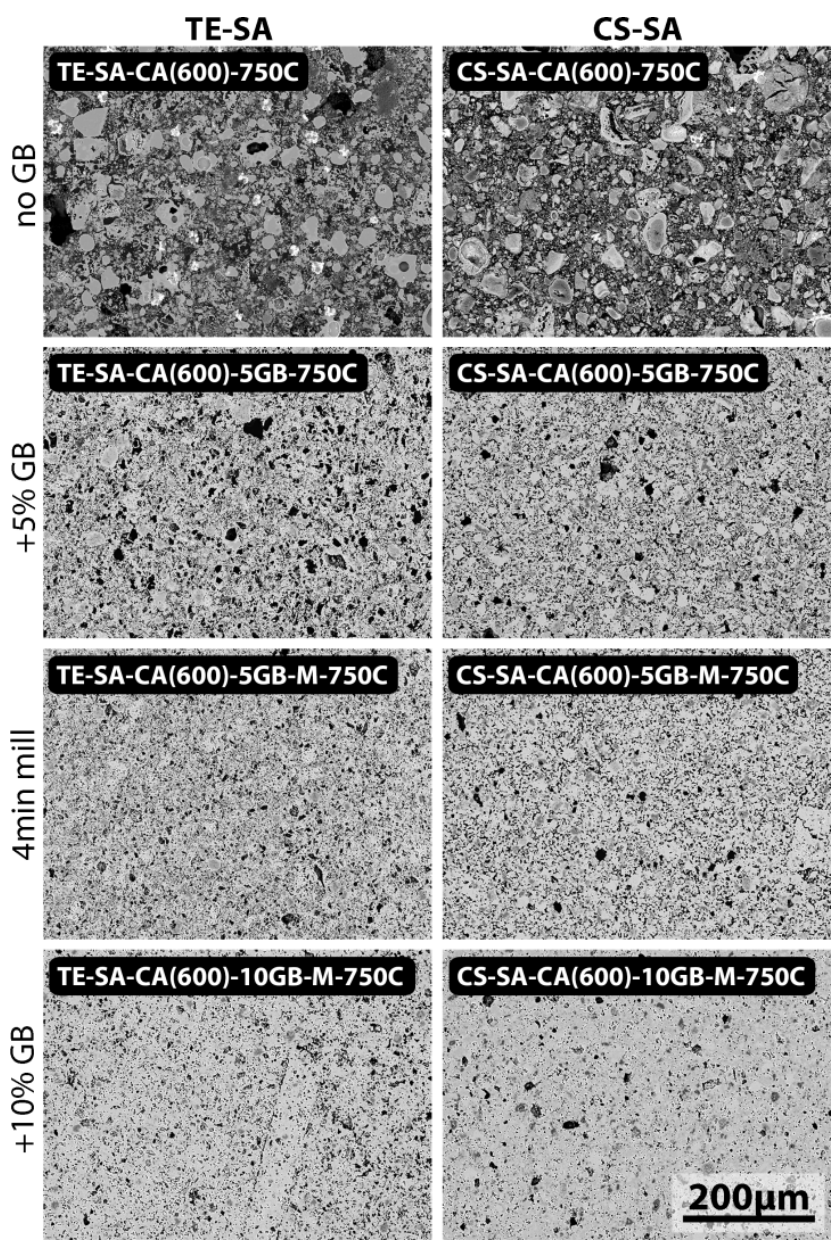

Figure 7. SEM micrograph collage showing progression of microstructure with incremental improvements (shown on the left) in both TE-SA and CS-SA sodalites. 


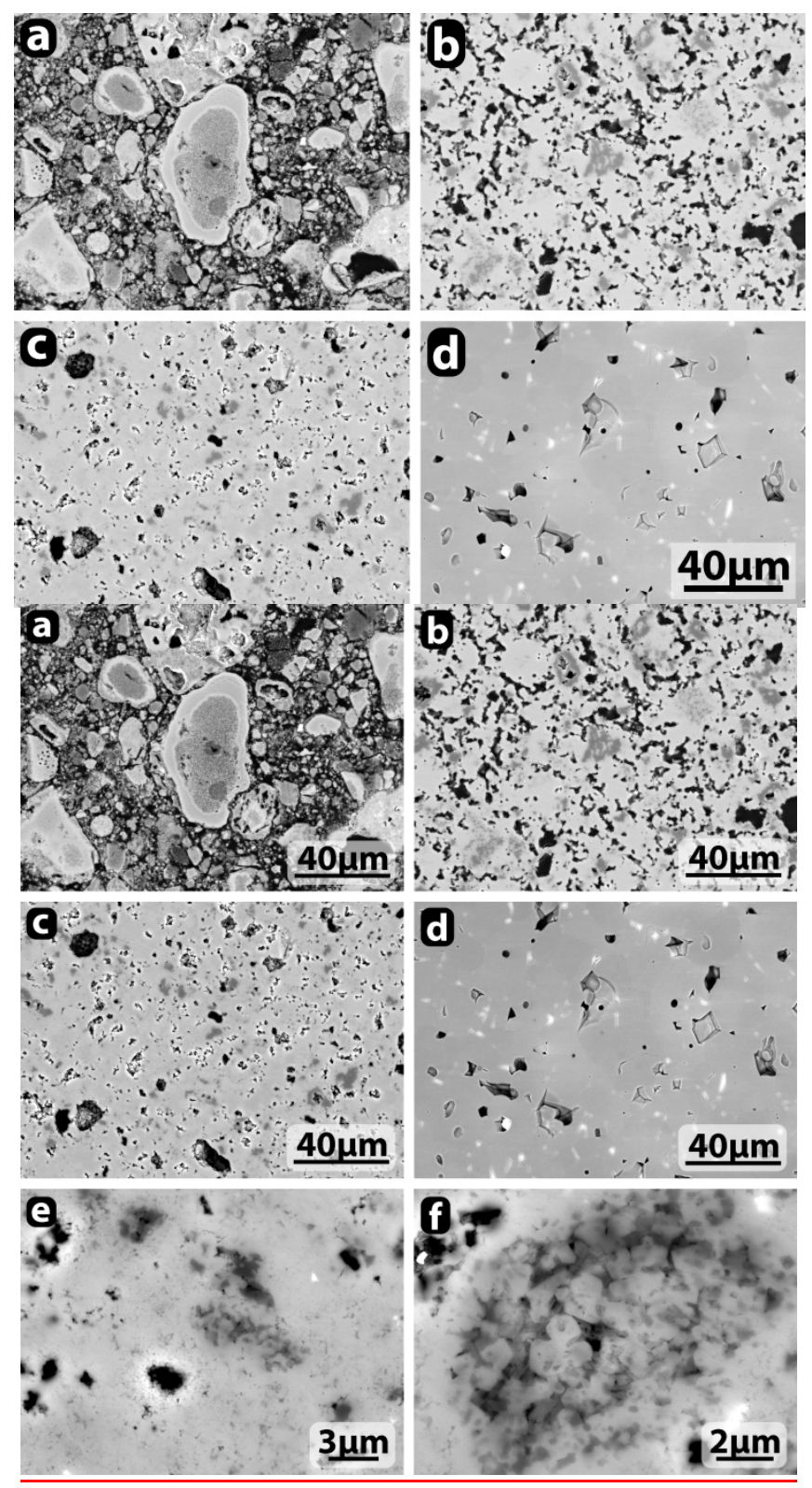

Figure 8. SEM micrographs showing the progression of porosity in the CS-SA specimens with higher magnification than Figure 7: a) CS-SA-CA600-750, b) CS-SA-CA600-5GB-M750, c) CS-SA-CA600-10GB-M-750, and-d) CS-SA-CA600-10GB-M-HUP, e) higher magnification of $d$ ) showing some voids, and f) higher magnification of d) showing sodalite crystallites within a low-density region. 


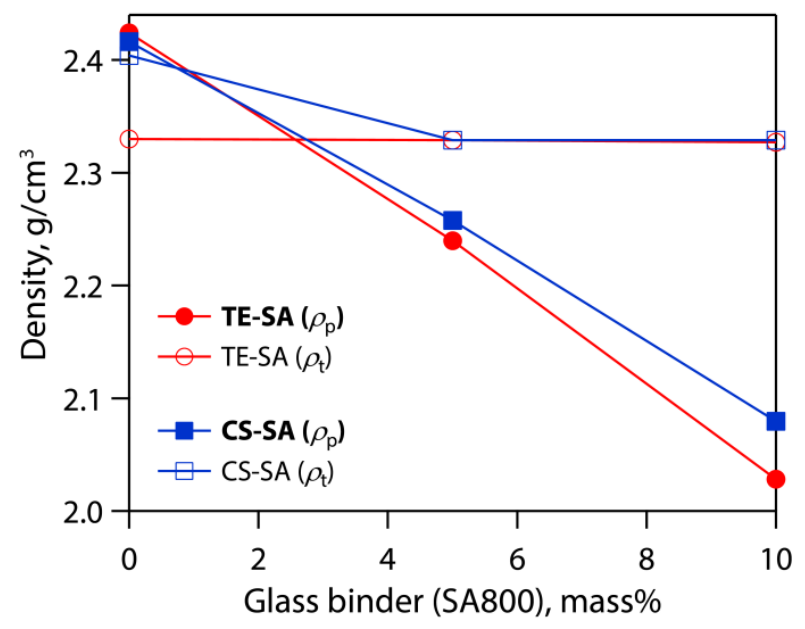

Figure 9. Comparison between $\rho_{\mathrm{p}}$ and $\rho_{\mathrm{t}}$ for TE-SA and CS-SA specimens, i.e., -CA(600)750C (0\% GB), -CA(600)-5GB-M-750C (5\% GB), and -CA(600)-10GB-M-750C (10\% GB). 
$\underline{\text { Tables }}$

Table 1. Reduced composition of OR salt and composition used for solution-based process. *The $\mathrm{SrCl}_{2}$ includes the $\mathrm{BaCl}_{2}$ fraction.

\begin{tabular}{lcc}
\hline Component & Mass \% & g/mL \\
\hline $\mathrm{LiCl}$ & 96.3 & $2.00 \mathrm{E}-01$ \\
$\mathrm{Li}_{2} \mathrm{O}$ & 1.97 & $4.10 \mathrm{E}-03$ \\
$\mathrm{CsCl}$ & 0.737 & $9.30 \mathrm{E}-05$ \\
$\mathrm{BaCl}_{2}$ & 0.660 & - \\
$\mathrm{SrCl}_{2}{ }^{*}$ & 0.318 & $2.03 \mathrm{E}-03$ \\
$\mathrm{LiI}$ & 0.0447 & $1.53 \mathrm{E}-03$ \\
\hline SUM: & $\mathbf{1 0 0 . 0 0}$ & - \\
\hline
\end{tabular}

Table 2. Sample naming conventions.

\begin{tabular}{ll}
\hline Designation & Description \\
\hline TE & tetraethyl orthosilicate used as silica source \\
CS & colloidal silica used as silica source \\
SG & sol-gel \\
SA & sodium aluminate $\left(\mathrm{NaAlO}_{2}\right)$ \\
LA & lithium aluminate $\left(\mathrm{LiAlO}_{2}\right)$ \\
CA & calcined (with temperature in parenthesis, $\left.{ }^{\circ} \mathrm{C}\right)$ \\
750 & firing temperature $\left({ }^{\circ} \mathrm{C}\right)$ \\
5 GB & 5 mass $\%$ glass binder \\
$10 G B$ & 10 mass\% glass binder \\
M & mixed for 4 min instead of 0.5 min \\
HUP & hot uniaxial press $\left(750{ }^{\circ} \mathrm{C}, 30\right.$ min $)$ \\
\hline
\end{tabular}




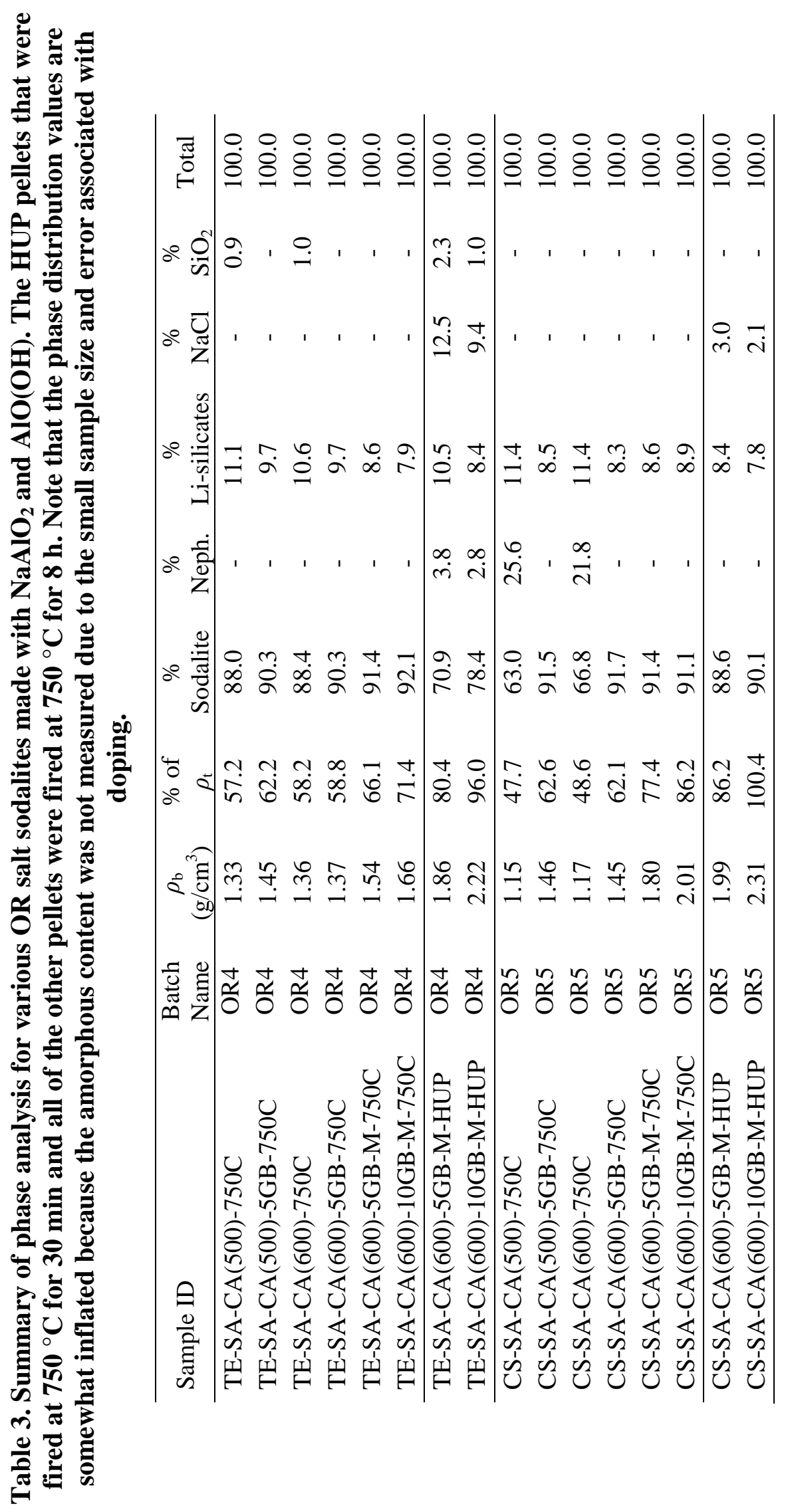

